\title{
Profile of Deaths in HIV Infected Patients: A 5 Year Retrospective Study from Western Maharashtra
}

\author{
Taware Ajay A ${ }^{1}$, Punpale Satyanarayan $\mathbf{B}^{2}$, Jadhao Vijay $\mathbf{T}^{1}$, Tatiya Harish $\mathbf{S}^{3}$, Bandgar Abhijit $\mathbf{L}^{3}$, \\ Vaidya Hemant $\mathrm{V}^{3}$, Bhosale Ashwini $\mathbf{A}^{\mathbf{4}}$ \\ ${ }^{I}$ Associate Professor, Department of Forensic Medicine and Toxicology, BJGMC, Pune, Maharashtra, India, \\ ${ }^{2}$ Professor, Department of Forensic Medicine and Toxicology, SKNMC, Pune, Maharashtra, India, ${ }^{3}$ Assistant \\ Professor, ${ }^{4}$ Postgraduate Student, Department of Forensic Medicine and Toxicology, BJGMC, Pune, Maharashtra, \\ India
}

\begin{abstract}
This is a retrospective study of deaths in human immunodeficiency virus (HIV) infected patients at Grant Medical college and Sir JJ group of hospitals, Mumbai from July 2000 up to June 2005 to determine statistical distribution with respect to age, sex and occupation, study clinical profile and causes of deaths among the HIV positive cases. For this we analysed the clinical records and autopsy reports of total 11092 deaths occurred during study period; out of these 1466 (13.2\%) were HIV positive deaths. Out of those 1466 HIV, maximum cases $(54 \%)$ were in the age group $31-40$ years; Males $(78 \%)$ clearly outnumbered the female population in the present study. Regarding occupation wise incidence, in 5\% cases factory workers were mainly affected. In the present study, clinically pulmonary tuberculosis was found in $40 \%$ cases, tuberculous meningitis was found in $21 \%$ cases and pneumonia was found in the $15 \%$ cases. Pulmonary tuberculosis was the immediate cause of death in $40 \%$ cases in the present study. Tuberculous meningitis and pneumonia were also the common causes of death in the present study.
\end{abstract}

Key WordS: HIV-AIDS, deaths, prevalence, clinical profile, tuberculosis.

\section{Introduction}

AIDS is retroviral disease caused by Human Immunodeficiency Virus. It is characterized by retroviral infection and depletion of CD $4_{+} \mathrm{T}$ - lymphocytes with profound immunosuppression leading to opportunistic infections, secondary neoplasms and neurological manifestations. ${ }^{1}$ The first case of AIDS was reported in the summer of 1981 from New York and California in

\section{Corresponding Author:}

\section{Punpale Satyanarayan B}

Professor, Department of Forensic Medicine and Toxicology, SKNMC, Pune, Maharashtra, India. Address: Flat B / 2, Satyaraj City Society, Survey no 49, Kale Borate Nagar, Hadapsar, Pune, Maharashtra, India. Pin code 411028, Mobile no +91 9860469512. Email: bandgarabhijit85@gmail.com
USA with a sudden increase in the incidence of two very rare diseases viz. Kaposi's sarcoma and Pneumocystis carinii pneumonia in homosexuals and young heroin addicts. $^{2}$ Since the first case report of AIDS in India in 1986 and the first autopsy report in 1988, the prevalence and seropositivity for HIV has been increasing every year, India is reported to have $3^{\text {rd }}$ largest HIV incidence in world, its prevalence in India constitutes 2.1 million people living with HIV as per 2014 data $^{3}$. Despite the disease's spread in India, very few reports on the prevalence and pathology of AIDS have been published. ${ }^{4}$ Therefore we attempted to assess the relative prevalence with respect to age, sex and occupation, clinical profile and autopsy analysis of HIV positive cases.

\section{Aims and Objectives}

To determine statistical distribution with respect to age, sex and occupation and study clinical profile among the HIV positive cases died during the study period.To 
analyze post mortem findings and causes of deathsamong the HIV positive cases subjected to autopsy during study period.

\section{Material and Methods}

For the present study, we retrospectively analysed the clinical records and autopsy reports of HIV positive cases from July 2000 up to June 2005 presented at Grant
Medical College and Sir JJ group of hospitals, Mumbai which is the largest state government hospital in state of Maharashtra. In the institution in total 11092 deaths occurred during study period; out of these 1466 were HIV positive deaths.

\section{Observations and Discussion}

Table No.1: Total HIV positive Deaths in Study Period

\begin{tabular}{|c|c|c|}
\hline Year & Total Deaths & HIV positive Deaths \\
\hline 2000 ( July to December) & 1310 & 166 \\
\hline 2001 & 2240 & 280 \\
\hline 2002 & 2135 & 289 \\
\hline 2003 & 2076 & 284 \\
\hline 2004 & 2254 & 185 \\
\hline 2005 ( January to June) & 1077 & 1466 \\
\hline Total & 11092 & 289 \\
\hline
\end{tabular}

Table No. 1 showing year wise distribution of HIV positive deaths. In the present study, the total deaths occurred were 11,092 from July 2000 to June, 2005. Out of these, 1466 (13.2\%) were HIV positive deaths.

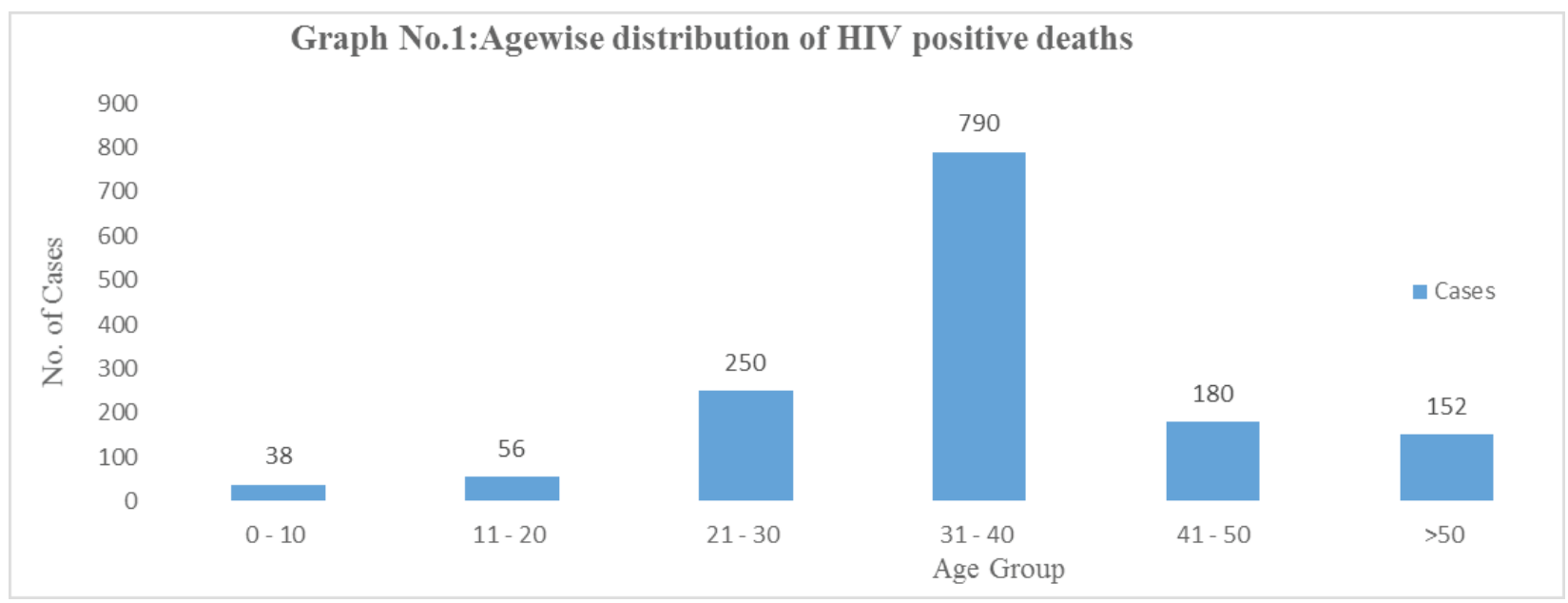

\section{Graph No.1: Age Wise Distribution of HIV Positive Deaths}

As can be seen in Graph No.1 The total number of HIV positive deaths in the $1^{\text {st }}$ decade of life were 38 , in the $2^{\text {nd }}$ decade were 56 , in the $3^{\text {rd }}$ decade were 250 , in the $4^{\text {th }}$ decade were 790 , in the $5^{\text {th }}$ decade were 180 and after the $5^{\text {th }}$ decade were 152 . These findings are consistent with study conducted by Sanaei-Zadeh ${ }^{5}$ where seropositive cases belonged to the age group between 20 to 40 years. 


\section{Graph No 2: Sexwise distribution of HIV positive deaths}

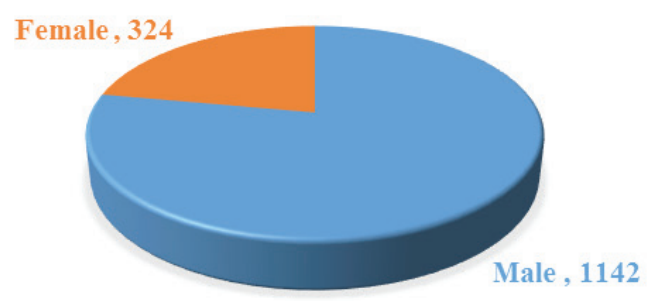

\section{Graph No.2: Sexwise Distribution Of HIV Positive Deaths}

Graph No.2 showing sex wise distribution, out of the 1466 cases studied, 324 were females while 1142 (78\%) were males. These findings matches with study conducted by Daniel Resnick et al ${ }^{6}$; while similar study conducted by M. P. Pradeep Kumar et al ${ }^{7}$ observed the prevalence equal among the both sexes in autopsy population, this might be due to smaller study population ( 11 cases) in later study.

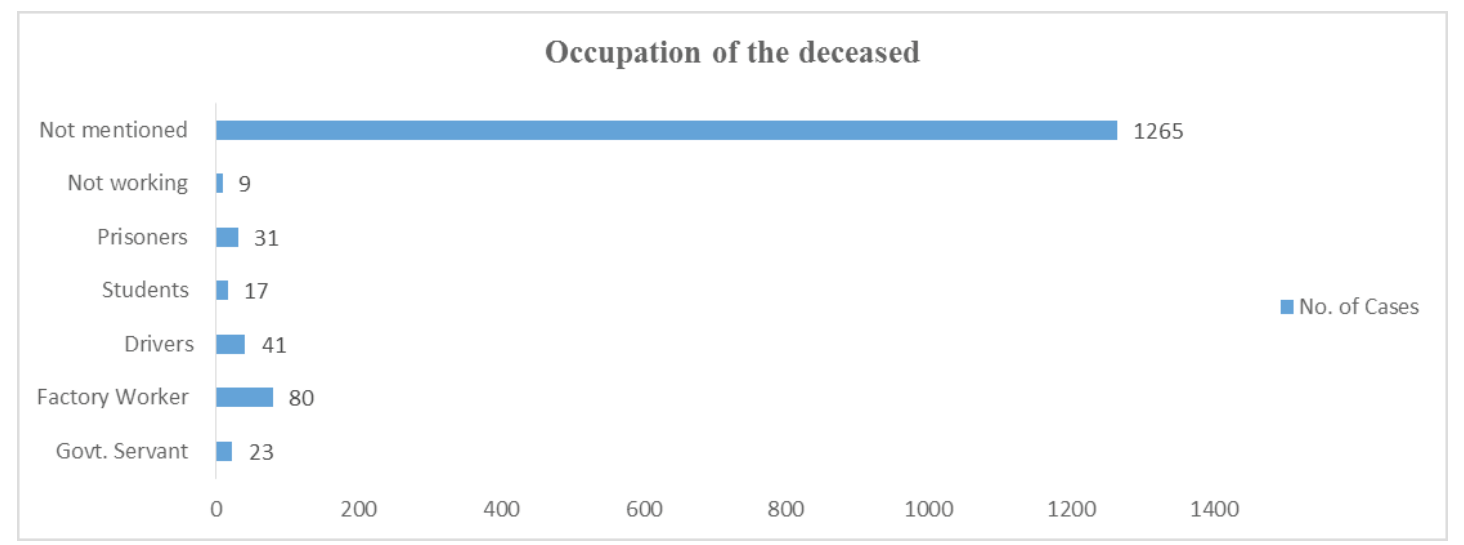

Graph No.3: Occupation Wise Distribution Of HIV Positive Deaths

Graph no 3 showing occupation wise distribution of HIV positive deaths. In the present study, 23 cases were government servants, 80 cases were factory workers, 41 cases were drivers, 17 cases were students, 31 cases were prisoners, 9 cases were not working and in 1265 cases data were not available. In a study by Sankaran ${ }^{8}$ showed that the high-risk group belonged to- sex workers, migrant workers, truck drivers, intravenous (IV) drug abusers and street dwellers.

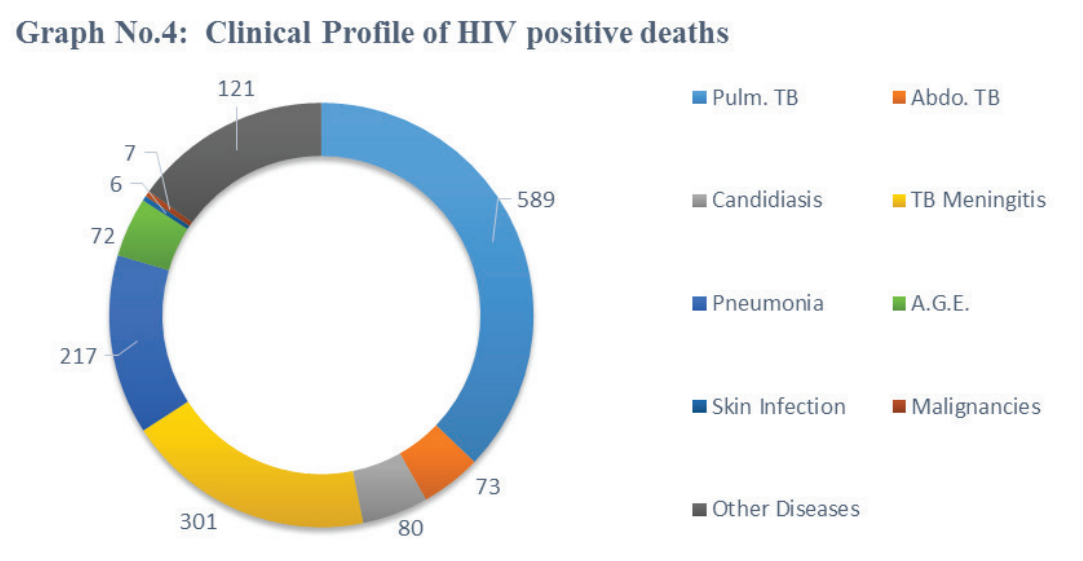


Graph no 4 shows the pattern of clinical findings in the HIV positive cases studied. Pulmonary tuberculosis was found in 589 cases, abdominal tuberculosis in 73 cases, candidiasis in 80 cases, tuberculous meningitis in 301 cases, pneumonia in 217 cases, acute gastroenteritis in 72 cases, skin infection in 6 cases, malignancies in 7 cases and in 121 cases other diseases were found. These findings are consistent with study conducted by $\mathrm{N}$ Kumarasamy et al ${ }^{9}$ about the clinical presentation in HIV infected patients.

Table 2: Causes Of Death In HIV Positive Deaths

\begin{tabular}{|c|c|c|}
\hline Cause of Death & No. of Cases & \% (n=1466) \\
\hline Pulmonary TB & 589 & 50.18 \\
\hline Abdominal TB & 73 & 14.80 \\
\hline Pneumonia & 217 & 20.52 \\
\hline TB Meningitis & 301 & 04.91 \\
\hline A.G.E. & 72 & 0.48 \\
\hline Malignancies & 07 & 0.67 \\
\hline Multiple Injuries & 10 & 0.28 \\
\hline Burns & 4 & 13.16 \\
\hline Others & 193 & \\
\hline Total & 1466 & 5 \\
\hline
\end{tabular}

Table No 3 showing the pattern of causes of death in all the HIV positive cases studied. Thus pulmonary tuberculosis, as a cause of death was found in 589 cases, abdominal tuberculosis in 73 cases, pneumonia in 217 cases, tuberculous meningitis in 301 cases, acute gastroenteritis in 72 cases, malignancies in 7 cases, multiple injuries in 10 cases, burns in 4 cases and other causes of deaths were found in 193 cases. These findings matches with studies of Lanjewar et $\mathrm{al}^{10}$ and Amarapurkar et $\mathrm{al}^{11}$.

\section{Conclusion}

The present study concludes as, the study includes 1466 HIV positive cases admitted to hospital for treatment and died due to AIDS. Maximum cases (54\%) were in the age group 31-40 years. Males (78\%) clearly outnumbered the female population in the present study. AIDS was found in $78 \%$ case in males and in $22 \%$ cases in females. Regarding occupation wise incidence, in majority of cases $(86 \%)$ data was not mentioned in clinical records. However, from amongst the data available, in 5\% cases factory workers were mainly affected. In the present study, clinically pulmonary tuberculosis was found in $40 \%$ cases, tuberculous meningitis was found in $21 \%$ cases and pneumonia was found in the $15 \%$ cases. Pulmonary tuberculosis was the immediate cause of death in $40 \%$ cases in the present study. Tuberculous meningitis and pneumonia were also the common causes of death in the present study. 
Source of Funding: None

Ethical Clearance: Nil.

\section{Conflict of Interest: Nil}

\section{References}

1. Vinay Kumar, Abdul K Abbas, Nelson FaustoDiseases of Immune System: Robbins Basic Pathology $8^{\text {th }}$ Edition; Saunders Pennsylvania, 2001, 155-65.

2. Braunwald $\mathrm{E}$ et al. Human Immunodeficiency virus (HIV) Disease: AIDS and related disorders. Harrison's principles of internal medicine. $15^{\text {th }}$ 2001; 2: 1852-1913.

3. Justice K Kannan -HIV and AIDS: Legal and Ethical Implications. A textbook of Medical Jurisprudence and Toxicology. $25^{\text {th }}$ Edition. 2015; $141-42$.

4. Lanjewar DN, Jain PP, Shetty SR. Profile of Central Nervous System Pathology in AIDS; an Autopsy Study from India. 1988; 12; $309-313$.

5. Sanaei-Zadeh H, Amoei M, Taghaddosinejad F. Seroprevalence of HIV, HBV and HCV in forensic autopsies, of presumed low risk, in Tehran, the capital of Iran. J Clin Forensic Med 2002; 9:17981.

6. Resnick D, Hellman F, Mirchandani H, Goodman DB. Human immunodeficiency virus infection in cases presenting to the Philadelphia Medical Examiner's Office. Am J Forensic Med Pathol 1991; 12:200-203.

7. MP Pradeep Kumar et al. Prevalence of HIV among bodies subjected for autopsy. Eur J Forensic Sci Jan - Mar 2015; Vol 2; Issue 1.

8. Sankaran JR. Current situation of HIV/AIDS in India and our response.J Indian AcadClin Med 2006; 7; $13-15$.

9. N Kumaraswamy et al. Clinical Profile of HIV In India. Indian J Med Res 121, April 2005; 377 394.

10. Lanjewar DN, Duggal R - Pulmonary pathology in patients with AIDS: A Pathological study from Mumbai. HIV Med 2001; 2; 266 - 271.

11. Anjali D Amarapurkar, NA Sangle. Hostological spectrum of liver in HIV- Autopsy study. Ann Hepatol. 2005; 4 (1): 47 - 51. 